\title{
Severe anaphylaxis requiring continuous adrenaline infusion during oral food challenge: a case series
}

\author{
Aiko Honda ${ }^{1}$, Takanori Imai ${ }^{2}$, Chihiro Kunigami ${ }^{1}$, Mayu Maeda ${ }^{2}$, Yuki Okada ${ }^{2}$, Toshinori \\ Nakamura $^{2}$, and Taro Kamiya ${ }^{2}$ \\ ${ }^{1}$ Showa University \\ ${ }^{2}$ Showa University School of Medicine
}

February 25, 2022

\begin{abstract}
Background: The primary treatment for anaphylaxis is intramuscular injection of adrenaline, but sometimes the response to treatment is inadequate and continuous intravenous administration of adrenaline is required. However, there is a lack of knowledge on the frequency and optimal method of administration. We aimed to report cases in which continuous adrenaline infusion was required during oral food challenges (OFCs) at our hospital. Method: We retrospectively reviewed the medical records of the last 6 years for cases of continuous Adrenaline administration in OFC. Result: Of 8531 patients, 214 patients received intramuscular adrenaline injection, and 7 patients required continuous administration. The reason for initiation of continuous administration was cardiovascular symptoms in all patients, one of which was associated with severe upper airway obstruction. All patients received intravenous fluid bolus, and one needed endotracheal intubation. Continuous infusion was started at $0.02-0.04 \mu \mathrm{g} / \mathrm{kg} / \mathrm{min}$, and because of prolonged hypotension in two patients, the dose had to be increased. Thereafter, all patients improved, and continuous administration was discontinued at a median of 155 (IQR:145-190) minutes. All patients had no adverse events or biphasic reactions. Conclusion: Continuous adrenaline administration in OFC was successful at 0.04$0.06 \mu \mathrm{g} / \mathrm{kg} / \mathrm{min}$ in treating severe anaphylaxis refractory to multiple intramuscular injections of adrenaline, and therapeutic response was achieved at a lower dose than previously recommended $(0.1-1.0 \mu \mathrm{g} / \mathrm{kg} / \mathrm{min})$.
\end{abstract}

\section{Conflict of interest}

The authors have no conflict of interest to declare.

\section{Abstract}

Background: The primary treatment for anaphylaxis is intramuscular injection of adrenaline, but sometimes the response to treatment is inadequate and continuous intravenous administration of adrenaline is required. However, there is a lack of knowledge on the frequency and optimal method of administration. We aimed to report cases in which continuous adrenaline infusion was required during oral food challenges (OFCs) at our hospital.

Method: We retrospectively reviewed the medical records of the last 6 years for cases of continuous Adrenaline administration in OFC.

Result: Of 8531 patients, 214 patients received intramuscular adrenaline injection, and 7 patients required continuous administration. The reason for initiation of continuous administration was cardiovascular symptoms in all patients, one of which was associated with severe upper airway obstruction. All patients received intravenous fluid bolus, and one needed endotracheal intubation. Continuous infusion was started at 0.02-0.04 $\mu \mathrm{g} / \mathrm{kg} / \mathrm{min}$, and because of prolonged hypotension in two patients, the dose had to be increased. Thereafter, 
all patients improved, and continuous administration was discontinued at a median of 155 (IQR:145-190) minutes. All patients had no adverse events or biphasic reactions.

Conclusion: Continuous adrenaline administration in OFC was successful at 0.04-0.06 $\mu \mathrm{g} / \mathrm{kg} / \mathrm{min}$ in treating severe anaphylaxis refractory to multiple intramuscular injections of adrenaline, and therapeutic response was achieved at a lower dose than previously recommended $(0.1-1.0 \mu \mathrm{g} / \mathrm{kg} / \mathrm{min})$.

\section{Key Message}

Severe anaphylaxis cases who need continuous intravenous adrenaline infusion in oral food challenges are rare, so appropriate treatment methods have yet to be established. We suggest a strategy for anaphylaxis refractory to intramuscular injections of adrenaline by presenting our cases.

\section{Key words}

Food allergy, Anaphylaxis, Oral food challenge, Adrenaline, continuous infusion

\section{Authors' Contributions}

$\mathrm{AH}$ is the first author of this manuscript. TI ,CK, MM, YO, TN, and TK critically revised the manuscript. All authors reviewed and approved the final manuscript.

\section{Introduction}

Oral food challenge (OFC) is the gold standard for diagnosing food allergies [1]. Some patients present with anaphylaxis and require intramuscular (IM) adrenaline injections. Previous studies reported that among pediatric patients with positive reactions during OFCs, 9-11\% needed adrenaline injection $[2,3]$. Furthermore, a previous study reported that $6 \%$ of reactions treated with adrenaline required multiple IM adrenaline injections when the symptoms persisted [4]. While most patients with anaphylaxis recover after IM adrenaline injection, patients requiring multiple doses are likely to require continuous adrenaline infusion [5]. In the Japanese food allergy guideline, the strategy is recommended is to be considered when response to treatment is not enough [6]". Other guidelines for anaphylaxis recommend that only specialists use continuous adrenaline infusion because of adverse effects due to inappropriate dosage $[7,8]$. Since patients who need continuous adrenaline infusion are limited, there are no randomized controlled trials or systematic reviews available. Recommendations for infusion doses are based on the physician's experience.

We conducted a case-series study in the pediatric department in the Showa University Hospital. We aimed to analyze the patients who needed continuous adrenaline infusion during OFCs and suggest appropriate timing to start the therapy and the optimal dose.

Our hospital has provided OFCs with physicians and nurses trained in emergency interventions based on the pediatric advanced life support system. All medical equipment and infusion procedures were prepared according to the patients' body weights before commencing the OFCs. A rapid response team consisting of medical emergency staff is arranged to be on call in the case of life-threatening events. IM adrenaline injection $(0.01 \mathrm{mg} / \mathrm{kg})$ was administered in accordance with the Japanese food allergy guideline [6]. In cases of anaphylactic shock, or symptoms requiring more than two doses of IM adrenaline, we immediately followed venous administration. Patients who required continuous adrenaline infusion were treated proactively if they showed severe symptoms refractory to IM adrenaline injection more than three times with appropriate support therapy, or if the effect of the medicine continued to incompletely improve the symptoms.

This study was approved by the ethics committee of the Showa University Hospital (approval number: 3486).

\section{Results}

There was a total of 8,569 OFCs, and 2,231 (26.0\%) positive results from March 2015 to February 2021. Of the 2,231 positive OFCs, 214 (9.6\%) patients received adrenaline. Among these patients, $41(19.2 \%)$ patients were given more than 2 doses of adrenaline, and 7 (3.3\%) patients required continuous adrenaline infusion. We present the OFC records of these 7 patients. 
The onset time represents the period from completion of the first intake of the allergen. Adverse events associated with continuous adrenaline infusion were also evaluated, including tachycardia, tremor, and pallor with increased blood pressure.

Case 1

A 5-year-old boy underwent an OFC with $3 \mathrm{~g}$ udon noodle (wheat). He had completely eliminated wheat because of a history of generalized rash and wheezing. Fourteen minutes after consuming the full amount of the allergenic food, he presented with a runny nose and mild cough. At $28 \mathrm{~min}$, the cough worsened, accompanied by oxygen desaturation $\left(\mathrm{SpO}_{2} 91 \%\right)$, therefore short-acting $\beta 2$-agonist (SABA) was administered. However, the symptoms persisted, and $\mathrm{SpO}_{2}$ did not improve from 91-94\%; IM adrenaline and oxygen was administered at $39 \mathrm{~min}$. Despite these treatments, respiratory symptoms persisted; therefore, SABA and IM adrenaline were re-administered at $46 \mathrm{~min}$ and $54 \mathrm{~min}$. Respiratory symptoms improved, followed by extensive urticaria and erythema at 105 min. During observation of the skin symptoms after administration of an antihistamine agent, he suddenly became pale, with tachycardia, and hypotension (systolic blood pressure, $60 \mathrm{mmHg}$ ) at $136 \mathrm{~min}$. A third IM adrenaline injection was administered with a fluid bolus at $142 \mathrm{~min}$, and continuous adrenaline infusion was immediately started at a dose of $0.03 \mu \mathrm{g} / \mathrm{kg} / \mathrm{min}$. Although he needed a fluid bolus again for tachycardia and hypotension at $240 \mathrm{~min}$, the symptoms abated $15 \mathrm{~min}$ later and did not require an increase in the infusion rate of adrenaline. The vital signs and general condition stabilized; therefore, adrenaline infusion was stopped at $330 \mathrm{~min}$.

Case 2

A 6-year-old girl who had eliminated wheat because of a history of respiratory symptoms due to udon noodle (wheat) retried the OFC with $1 \mathrm{~g}$ udon noodles. Twenty-four minutes after ingestion of $1 \mathrm{~g}$ of udon, she reported discomfort around her throat, and wheezing. The respiratory symptoms worsened; therefore, we administered inhaled SABA twice, followed by IM adrenaline at $37 \mathrm{~min}$ because the respiratory condition had failed to improve. At $47 \mathrm{~min}$, she showed obvious dyspnea and decreased $\mathrm{SpO}_{2}$ to $92 \%$, so a second IM adrenaline injection was administered. Although these symptoms temporarily improved, systemic urticaria and desaturation flared up at $84 \mathrm{~min}$, and systolic blood pressure decreased to $72 \mathrm{mmHg}$. We administered the third and fourth IM adrenaline doses at 87 and 88 minutes, respectively. Soon after administration of fluid bolus and the fourth IM adrenaline injection, continuous adrenaline infusion $(0.04 \mu \mathrm{g} / \mathrm{kg} / \mathrm{min})$ was started (89 minutes). The rate was raised to $0.06 \mu \mathrm{g} / \mathrm{kg} / \mathrm{min} 14$ minutes later due to inadequate effect on hypotension. The vital signs and general condition stabilized, and the infusion rate was tapered and discontinued 145 min later.

Case 3

A 6-year-old boy underwent an OFC with peanuts. He had completely eliminated peanuts because of acute symptoms after consumption of nut cake. After consuming $3 \mathrm{~g}$ of peanuts, he experienced discomfort in the mouth and throat. After 42 min, erythema spread to the neck and abdomen, and antihistamine agents were administered. At 56 minutes, he presented with a wheeze and oxygen desaturation $\left(\mathrm{SpO}_{2} 93 \%\right)$, so SABA was administered. The symptoms did not abate, and the erythema spread to the entire body. IM adrenaline and oxygen were given at $65 \mathrm{~min}$. Although his condition stabilized at $95 \mathrm{~min}$, he suddenly presented with decreased consciousness during urination and fainted. Secondary adrenaline was immediately administered, but the systolic blood pressure decreased to a low of $48 \mathrm{mmHg}$. A third IM adrenaline injection and fluid bolus were administered, and a continuous adrenaline infusion was also prepared. After initiation of continuous adrenaline infusion at $0.03 \mu \mathrm{g} / \mathrm{kg} / \mathrm{min}$, his vital signs and condition stabilized, and infusion was discontinued after 155 minutes.

Case 4

An 8-year-old boy underwent an OFC with raw Chinese yam. He had developed facial swelling and a cough after ingestion of Chinese yam when he was 6 years old. Soon after ingesting a few grams of Chinese yam, he experienced discomfort in his mouth and presented with a mild cough. At 3 min, the cough appeared 
to be significant. At 20 minutes, he showed moderate abdominal pain and declining activity; therefore, IM adrenaline and oxygen were administered. After treatment, the symptoms disappeared, but urticaria occurred at 65 min and spread systemically. Almost simultaneously, he presented with tachycardia and remarkable hypotension (sBP $30 \mathrm{mmHg}$ ), and finally lost consciousness. IM adrenaline was immediately administered at $75 \mathrm{~min}$, but hypotension persisted (BP $65 / 30 \mathrm{mmHg}$ ). At $80 \mathrm{~min}$, a third dose of IM adrenaline and fluid bolus were administered. For persistent hypotension, continuous adrenaline infusion was administered at $0.03 \mu \mathrm{g} / \mathrm{kg} / \mathrm{min}$ at 95 minutes. Shortly after we confirmed that his systolic blood pressure had improved to $90 \mathrm{mmHg}$, he was hospitalized. The vital signs and general condition were stabilized, so the infusion rate was gradually decreased over a period of 120 min and discontinued.

Case 5

The patient was a 10-year-old boy who was able to consume raw eggs without problems at rest, but anaphylaxis was observed immediately after exercise, in accordance with ingestion. Therefore, food-dependent exercise-induced anaphylaxis (FDEIA) was suspected. In line with our protocol for the diagnosis of FDEIA, he was administered aspirin $10 \mathrm{mg} / \mathrm{kg}$, and three raw eggs. During the bed stay after ingestion, the patient did not display any symptoms. After $60 \mathrm{~min}$ of observation, he ran for $15 \mathrm{~min}$ while maintaining a heart rate of over 180/min. Immediately after exercise, he developed severe eyelid swelling, urticaria on his abdomen, and wheezing, successively within a few minutes. While preparing the SABA inhaler, he suddenly showed decreased consciousness and restlessness; therefore, IM adrenaline was immediately administered 4 minutes after exercise. However, his systolic blood pressure decreased to $60 \mathrm{mmHg}$, and he showed signs of airway obstruction and dyspnea; therefore, IM adrenaline was repeatedly administered a total of 4 times every few minutes. Twenty minutes after exercise, a fluid bolus $(10 \mathrm{ml} / \mathrm{kg})$ and adrenaline intravenous infusion were started at $0.02 \mu \mathrm{g} / \mathrm{kg} / \mathrm{min}$. Since the low blood pressure persisted, we increased the rate to $0.04 \mu \mathrm{g} / \mathrm{kg} / \mathrm{min}$ 5 minutes later. His condition gradually improved, except for temporary mild wheezing, and the infusion rate was decreased and discontinued at $164 \mathrm{~min}$.

Case 6

An 11-year-old boy underwent an OFC with milk. At the age of 5 months, he had immediate symptoms after ingestion of formula, but subsequent OFCs were negative; therefore, he had ingested $3 \mathrm{ml}$ of milk. At the OFC, soon after ingestion of $8 \mathrm{ml}$, the patient vomited and developed a severe urticaria. After $5 \mathrm{~min}$, the patient suddenly became pale and lost consciousness. IM adrenaline was administered three times for shock symptoms at 6,8 , and 11 min. However, his cardiovascular symptoms did not improve, and he finally developed respiratory failure. At 15 minutes, continuous adrenaline infusion $(0.03 \mu \mathrm{g} / \mathrm{kg} / \mathrm{min})$ and fluid bolus were started. Despite treatment, respiratory failure progressed, and he finally required intubation at 61 minutes. His condition gradually improved without increasing the rate of adrenaline infusion. Continuous adrenaline infusion was discontinued $190 \mathrm{~min}$ later and the intubation tube was removed the next day. The patient was discharged on the following day.

\section{Case 7}

A 17-year-old boy underwent an OFC with multiple nuts. He consumed $3 \mathrm{~g}$ of cashews, walnuts, and macadamias simultaneously. He had never eaten these nuts before because his immunoglobulin E (IgE) levels were positive. At 21 minutes after ingestion, he presented with erythema of the face and discomfort of the throat. Urticaria gradually spread to the whole body at $54 \mathrm{~min}$, and he presented with tachycardia (heart rate $[\mathrm{HR}], 133 / \mathrm{min})$ and oxygen desaturation $\left(\mathrm{SpO}_{2} 94 \%\right)$ at 67 minutes, so IM adrenaline, oxygen, and fluid bolus $(10 \mathrm{~mL} / \mathrm{kg})$ were administered. As the shock symptoms did not improve, a second IM adrenaline injection was administered at $94 \mathrm{~min}$. The symptoms improved for a while, but at $132 \mathrm{~min}$, tachycardia (HR 140/min) and hypotension (blood pressure, $85 / 38 \mathrm{mmHg}$ ) recurred. Even after the third adrenaline administration at 153 min, significant tachycardia and hypotension persisted, so fluid bolus was administered again, and continuous adrenaline infusion was started at $160 \mathrm{~min}$. Six minutes after starting the continuous infusion, vital signs and general condition stabilized. Continuous adrenaline infusion was discontinued 151 minutes later. 


\section{Summary of results}

The baseline characteristics of the patients are presented in Table 1. The range of age at OFCs was 80-205 months, which is comparatively higher than all OFC patients (median: 47 months; inter-quartile range: 26-81 months). Among the seven patients, six were male. Asthma is the most common comorbidity in allergic diseases.

Detailed information on the adrenaline therapy is presented in Table 2. All patients presented with severe cardiovascular symptoms, and 6 of 7 patients showed respiratory symptoms. The total number of IM adrenaline injections administered was three to four. All patients were treated with a fluid bolus, and only one patient needed intubation for severe respiratory and cardiovascular symptoms.

The initial administration rate of adrenaline infusion was $0.02-0.04 \mu \mathrm{g} / \mathrm{kg} / \mathrm{min}$. Only two patients required an increase in the rate: 0.03 to $0.06 \mu \mathrm{g} / \mathrm{kg} / \mathrm{min}$, and 0.02 to $0.04 \mu \mathrm{g} / \mathrm{kg} / \mathrm{min}$. All patients stabilized after hospitalization, and intravenous adrenaline infusion was discontinued after roughly 3 hours. None of the patients presented with biphasic reactions.

\section{Discussion}

\section{Patient characteristics}

The results suggest that we could not predict severe anaphylaxis from patients' backgrounds. Almost half of the patients had no history of anaphylaxis in response to the causative food. A previous study evaluating the predictive factors of reactions during OFCs also reported that the clinical history of anaphylaxis to peanuts was not significantly associated with severe allergic reactions during OFCs [9]. In our study, the patients were older, and displayed a high rate of asthma complications, which is consistent with previous case reports [10]. Although there have only been a limited number of reports to date, it is necessary to pay attention to severe symptoms in children who are older and have a history of asthma.

\section{Symptoms during OFCs, and treatment}

Severe anaphylactic symptoms can develop suddenly or worsen rapidly, leading to anaphylactic shock. In our patients, while IM adrenaline was mostly administered 30-90 minutes after ingestion, two patients presented with severe symptoms immediately after food ingestion or exercise. Of note, all patients had cardiovascular symptoms. Considering the rapid worsening of allergic reactions, we acknowledged that providing prompt therapeutic intervention, and consensus on the treatment strategy must have been a crucial prerequisite for providing safe OFC.

We standardized the treatment corresponding to severe refractory anaphylaxis to multiple IM adrenaline injections; therefore, we adopted a $0.03 \mu \mathrm{g} / \mathrm{kg} / \mathrm{min}$ starting dose for continuous adrenaline infusion. This decision was based on the expectation that the risk of anaphylaxis is mitigated in the OFC because the challenged dose was set based on severity and immunological parameters, and the treatment was applied without delay. Therefore, we set this infusion rate to minimize the risk of treatment with adrenaline. Even in the two cases in which the required dose was increased, the patients were able to overcome anaphylaxis with appropriate dose increases based on their symptoms, and no serious sequelae were observed.

According to the current guideline, adrenaline infusion should be applied to patients who require repeated IM doses of adrenaline, but the appropriate infusion rate is not standardized [8]. The Japanese guidelines for food allergy recommends 0.1-1.0 $\mu \mathrm{g} / \mathrm{kg} / \mathrm{min}$ as the starting dose [6]. Barach et al. recommended an infusion rate of $0.1 \mu \mathrm{g} / \mathrm{kg} / \mathrm{min}$ for children and infants [11]. Brown and Alviani suggested $0.085-0.17 \mu \mathrm{g} / \mathrm{kg} / \mathrm{min}$ as the initial rate depending on the severity of the reaction $[5,12]$. The doses recommended in previous studies were relatively high compared to those used in our study. However, none of the patients presented with serious adverse events and all patients recovered completely. In addition, continuous adrenaline administration was discontinued in all the patients within a few hours. These facts suggest that the high infusion rate recommended in previous studies or guidelines might not be needed if appropriate therapy is provided. 
However, because of the small number of cases examined, this suggestion would need to be confirmed after studying further cases.

This was a case-series study performed during OFCs, and the amount of challenged food was determined based on the characteristics of previous episodes of the patients. Our results cannot be applied directly to accidental anaphylaxis in emergency departments; however, they will certainly be valuable in considering treatment options for severe anaphylaxis.

\section{Conclusion}

We cannot predict severe anaphylaxis prior to OFC; therefore, we should be prepared for the development of symptoms. In these case reports, continuous adrenaline infusion was effective in severe cases that did not respond to repeated IM adrenaline administration.

\section{References}

1. Sicherer, S.H. and H.A. Sampson, Food allergy. J Allergy Clin Immunol, 2010. 125 (2)(Suppl 2): p. S116-25.

2. Lieberman, J.A., et al., Outcomes of office-based, open food challenges in the management of food allergy. J Allergy Clin Immunol, 2011. 128 (5): p. 1120-2.

3. Perry, T.T., et al., Risk of oral food challenges. J Allergy Clin Immunol, 2004. 114 (5): p. 1164-8.

4. Järvinen, K.M., et al., Epinephrine treatment is infrequent and biphasic reactions are rare in food-induced reactions during oral food challenges in children. J Allergy Clin Immunol, 2009.124 (6): p. 1267-72.

5. Alviani, C., et al., Anaphylaxis Refractory to intramuscular adrenaline during in-hospital food challenges: A case series and proposed management. Clin Exp Allergy, 2020. 50 (12): p. 1400-5.

6. Ebisawa, M., K. Ito, and T. Fujisawa, Committee for Japanese Pediatric Guideline for Food Allergy, The Japanese Society of Pediatric Allergy and Clinical Immunology, Japanese Society of Allergology, Japanese guidelines for food allergy 2020. Allergol Int, 2020.69 (3): p. 370-86.

7. Soar, J., et al., Emergency treatment of anaphylactic reactions-Guidelines for healthcare providers. Resuscitation, 2008. 77 (2): p. 157-69.

8. Muraro, A., et al., Anaphylaxis: Guidelines from the European Academy of Allergy and Clinical Immunology. Allergy, 2014.69 (8): p. 1026-45.

9. Arkwright, P.D., et al., Severity and threshold of peanut reactivity during hospital-based open oral food challenges: An international multicenter survey. Pediatr Allergy Immunol, 2018.29 (7): p. 754-61.

10. Niggemann, B., S. Yürek, and K. Beyer, Severe anaphylaxis requiring intensive care during oral food challenge-It is not always peanuts. Pediatr Allergy Immunol, 2017. 28 (2): p. 201-3.

11. Barach, E.M., et al., Epinephrine for treatment of anaphylactic shock. JAMA, 1984. 251 (16): p. 2118-22.

12. Brown, S.G., et al., Insect sting anaphylaxis; prospective evaluation of treatment with intravenous adrenaline and volume resuscitation. Emerg Med J, 2004. 21 (2): p. 149-54.

Table1. Baseline characteristics 


\begin{tabular}{|c|c|c|c|c|c|c|c|c|}
\hline case & $\begin{array}{l}\text { age } \\
\text { (months) }\end{array}$ & $\operatorname{sex}$ & $\begin{array}{l}\text { allergen } \\
\text { for OFC }\end{array}$ & $\begin{array}{l}\text { comorbidity } \\
\text { of allergic } \\
\text { disease }\end{array}$ & $\begin{array}{l}\text { allergy for } \\
\text { other } \\
\text { food } \\
\text { allergen }\end{array}$ & $\begin{array}{l}\text { total } \\
\operatorname{IgE}(\mathrm{IU} / \mathrm{mL})\end{array}$ & $\begin{array}{l}\text { specific } \\
\operatorname{IgE}(\mathrm{UA} / \mathrm{mL}\end{array}$ & $\begin{array}{l}\text { laxis d } \\
\text { to } \\
\text { causat } \\
\text { Jallerge }\end{array}$ \\
\hline 1 & 67 & male & $\begin{array}{l}\text { udon } \\
\text { noodle } 3 \mathrm{~g}\end{array}$ & $\mathrm{AD}$ & $\begin{array}{l}\text { hen's egg / } \\
\text { cow's milk } \\
\text { / tree nuts }\end{array}$ & 287 & $\begin{array}{l}89.7 \\
(\omega-5 \text { gliadin } \\
8.86)\end{array}$ & + \\
\hline 2 & 74 & female & $\begin{array}{l}\text { udon } \\
\text { noodle } 1 \mathrm{~g}\end{array}$ & $\mathrm{BA}$ & $\begin{array}{l}\text { hen's egg / } \\
\text { cow's milk } \\
\text { / peanut }\end{array}$ & 1876 & $\begin{array}{l}101 \\
(\omega-5 \text { gliadin } \\
6.73)\end{array}$ & - \\
\hline 3 & 80 & male & peanut $3 \mathrm{~g}$ & none & walnut & 690 & $\begin{array}{l}5.93(\text { Ara h } \\
27.25)\end{array}$ & + \\
\hline 4 & 106 & male & $\begin{array}{l}\text { raw chinese } \\
\text { yam }\end{array}$ & $\begin{array}{l}\mathrm{BA}, \mathrm{AD}, \\
\mathrm{AR}\end{array}$ & $\begin{array}{l}\text { peanut / } \\
\text { tree nuts / } \\
\text { crustacean }\end{array}$ & 2533 & 10.3 & - \\
\hline 5 & 130 & male & $\begin{array}{l}3 \text { raw hen's } \\
\text { egg }+ \\
\text { exercise }\end{array}$ & BA & none & 722 & $\begin{array}{l}<0.1 \\
\text { (ovomucoid } \\
<0.1)\end{array}$ & - \\
\hline 6 & 137 & male & $\begin{array}{l}\text { cow's } \\
\text { milk } \\
8 \mathrm{ml}\end{array}$ & $\begin{array}{l}\mathrm{BA}, \\
\mathrm{AD}, \mathrm{AR}\end{array}$ & $\begin{array}{l}\text { hen's } \\
\text { egg }\end{array}$ & 104 & 7.17 & + \\
\hline 7 & 205 & male & $\begin{array}{l}\text { cashew } \\
\text { nuts, } \\
\text { walnuts } \\
\text { and } \\
\text { macadamia } \\
\text { nuts } 3 g \text { for } \\
\text { each }\end{array}$ & $\mathrm{BA}, \mathrm{AD}$ & $\begin{array}{l}\text { hen's egg / } \\
\text { peanut } \\
\text { buckwheat } \\
\text { / shrimp }\end{array}$ & 671 & $\begin{array}{l}\text { cashew nut } \\
12.9 \text { walnut } \\
16.6\end{array}$ & - \\
\hline
\end{tabular}

BA: bronchial asthma AD: atopic dermatitis AR: allergic rhinitis

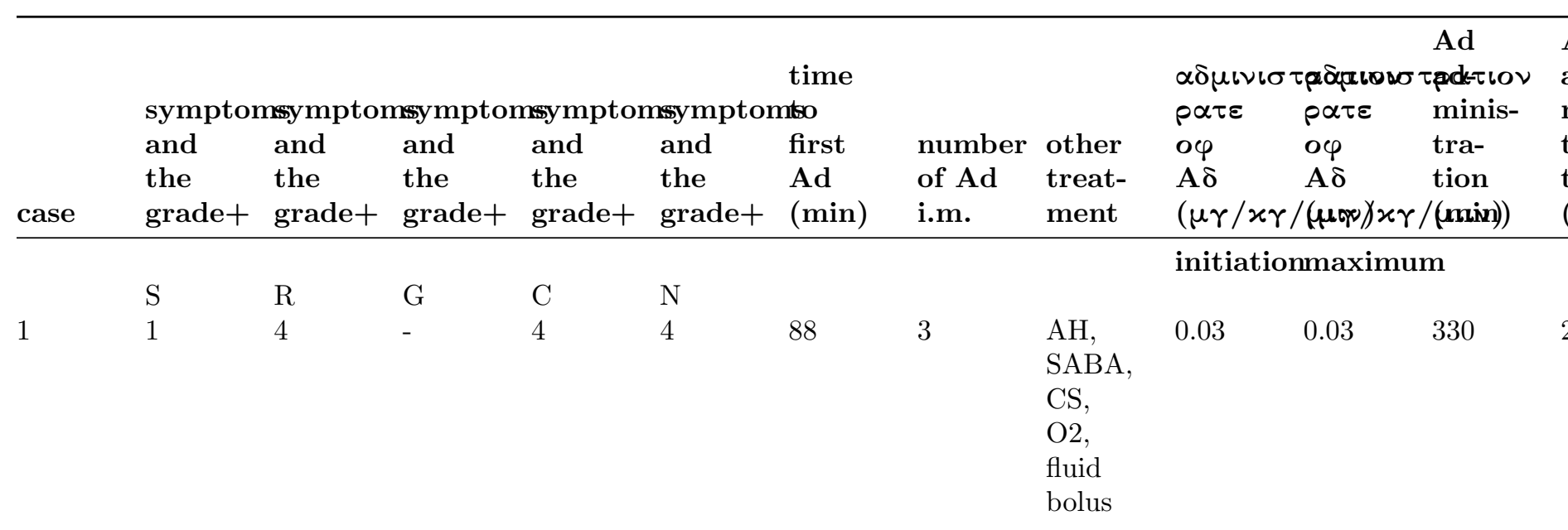




\begin{tabular}{|c|c|c|c|c|c|c|c|c|c|c|c|}
\hline case & $\begin{array}{l}\text { sympton } \\
\text { and } \\
\text { the } \\
\text { grade+ }\end{array}$ & $\begin{array}{l}\text { asympton } \\
\text { and } \\
\text { the } \\
\text { grade+ }\end{array}$ & $\begin{array}{l}\text { nsympton } \\
\text { and } \\
\text { the } \\
\text { grade+ }\end{array}$ & $\begin{array}{l}\text { nsymptor } \\
\text { and } \\
\text { the } \\
\text { grade+ }\end{array}$ & $\begin{array}{l}\text { nsymptor } \\
\text { and } \\
\text { the } \\
\text { grade+ }\end{array}$ & $\begin{array}{l}\text { time } \\
\text { ntso } \\
\text { first } \\
\text { Ad } \\
(\mathrm{min}) \\
\end{array}$ & $\begin{array}{l}\text { number } \\
\text { of Ad } \\
\text { i.m. }\end{array}$ & $\begin{array}{l}\text { other } \\
\text { treat- } \\
\text { ment }\end{array}$ & $\begin{array}{l}\alpha \delta \mu \iota \nu \iota \sigma \\
\rho \alpha \tau \varepsilon \\
o \varphi \\
\mathrm{A} \delta \\
\left(\mu \gamma /{ }^{\prime} / \gamma\right)\end{array}$ & 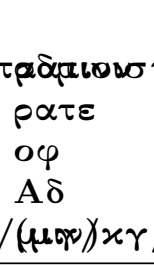 & 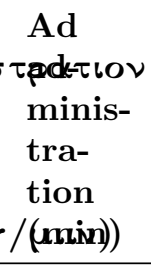 \\
\hline 2 & 2 & 4 & 3 & 4 & 4 & 37 & 4 & $\begin{array}{l}\text { SABA, } \\
\text { CS, } \\
\text { O2, } \\
\text { fluid } \\
\text { bolus }\end{array}$ & 0.04 & 0.06 & 145 \\
\hline 3 & 2 & 4 & - & 5 & 5 & 65 & 3 & $\begin{array}{l}\text { AH, } \\
\text { SABA, } \\
\text { CS, } \\
\text { O2, } \\
\text { fluid } \\
\text { bolus }\end{array}$ & 0.03 & 0.03 & 155 \\
\hline 4 & 2 & 4 & 3 & 5 & 5 & 25 & 3 & $\begin{array}{l}\text { AH, } \\
\text { SABA, } \\
\text { O2, } \\
\text { fluid } \\
\text { bolus }\end{array}$ & 0.03 & 0.03 & 120 \\
\hline 5 & 1 & 4 & - & 5 & 4 & 82 & 4 & $\begin{array}{l}\text { SABA, } \\
\text { CS, } \\
\text { O2, } \\
\text { fluid } \\
\text { bolus }\end{array}$ & 0.02 & 0.04 & 164 \\
\hline 6 & 1 & 5 & 3 & 4 & 5 & 6 & 3 & $\begin{array}{l}\text { CS, } \\
\text { O2, } \\
\text { fluid } \\
\text { bo- } \\
\text { lus, } \\
\text { intubation }\end{array}$ & 0.03 & 0.03 & 190 \\
\hline 7 & 2 & 3 & 2 & 4 & - & 67 & 4 & $\begin{array}{l}\text { AH, } \\
\text { CS, } \\
\text { O2, } \\
\text { fluid } \\
\text { bolus }\end{array}$ & 0.03 & 0.03 & 151 \\
\hline
\end{tabular}

Table 2, Treatment for anaphylaxis

+: Sampson's grade S: skin, R: respiratory, G: gastrointestinal, C: cardiovascular N: neurologic,

SABA: short-acting inhaled $\beta 2$-agonist AH: antihistamine agent CS: corticosteroid Ad: adrenaline

\section{Hosted file}

table.pptx available at https://authorea.com/users/462258/articles/557731-severe-anaphylaxisrequiring-continuous-adrenaline-infusion-during-oral-food-challenge-a-case-series 